\title{
DSM-5 PTSD and posttraumatic stress spectrum in Italian emergency personnel: correlations with work and social adjustment
}

This article was published in the following Dove Press journal:

Neuropsychiatric Disease and Treatment

18 February 2016

Number of times this article has been viewed

\author{
Claudia Carmassi ${ }^{1}$ \\ Camilla Gesi' \\ Marly Simoncini' \\ Luca Favilla' \\ Gabriele Massimetti \\ Maria Cristina Olivieri' \\ Ciro Conversano ${ }^{2}$ \\ Massimo Santini ${ }^{2}$ \\ Liliana Dell'Osso' \\ 'Department of Clinical and \\ Experimental Medicine, Section of \\ Psychiatry, University of Pisa, Pisa, \\ Italy; ${ }^{2}$ Emergency Medicine and \\ Emergency Room Unit, Azienda \\ Ospedaliero-Universitaria Pisana \\ (AOUP), Pisa, Italy
}

\begin{abstract}
The Diagnostic and Statistical Manual of Mental Disorders Fifth Edition (DSM-5) has recently recognized a particular risk for posttraumatic stress disorder (PTSD) among first responders (criterion A4), acknowledging emergency units as stressful places of employment. Little data is yet available on DSM-5 among emergency health operators. The aim of this study was to assess DSM-5 symptomatological PTSD and posttraumatic stress spectrum, as well as their impact on work and social functioning, in the emergency staff of a major university hospital in Italy. One hundred and ten subjects (doctors, nurses, and health-care assistants) were recruited at the Emergency Unit of the Azienda Ospedaliero-Universitaria Pisana (Italy) and assessed by the Trauma and Loss Spectrum-Self Report (TALS-SR) and Work and Social Adjustment Scale (WSAS). A 15.7\% DSM-5 symptomatological PTSD prevalence rate was found. Nongraduated persons reported significantly higher TALS-SR Domain IV (reaction to loss or traumatic events) scores and a significantly higher proportion of individuals presenting at least one maladaptive behavior (TALS-SR Domain VII), with respect to graduate ones. Women reported significantly higher WSAS scores. Significant correlations emerged between PTSD symptoms and WSAS total scores among health-care assistants, nongraduates and women. Our results showed emergency workers to be at risk for posttraumatic stress spectrum and related work and social impairment, particularly among women and nongraduated subjects.
\end{abstract}

Keywords: posttraumatic stress disorder (PTSD), emergency, emergency care workers, work and social functioning/adjustment, maladaptive behaviors, gender, education

\section{Introduction}

Medical and paramedical staff, particularly in service in emergency planning, are frequently exposed to situations of great physical and psychological stress. An increasing number of articles in the literature have focused on the development of psychic and somatic symptoms in the health workforce. Emergency Departments, in fact, may be challenging because of frequent unpredictability of daily work cases, coping with the acute phase of most disorders, and frequent facing of patient and their families' expectations in unexpected critical cases/situations. This has induced an increasing number of researchers to investigate work-related psychological disorders, such as burnout syndrome (BOS) and, more recently, posttraumatic stress disorder (PTSD). ${ }^{1-5}$

Burnout denotes an occupational health concept of emotional and physical exhaustion, depersonalization, and decreased personal accomplishment. BOS has been defined as a "state of physical, emotional and mental exhaustion caused by longterm involvement in emotional demanding situations" experienced in the workplace. ${ }^{2}$ This definition highlights BOS as a psychological state resulting from prolonged
Correspondence: Claudia Carmassi Department of Clinical and Experimental Medicine, University of Pisa, Via Roma 67, 56100 Pisa, Italy

Tel +390502219766

Fax +390502219787

Email ccarmassi@gmail.com
Neuropsychiatric Disease and Treatment 2016:12 375-38|

375

submit your manuscript

(c) (1) (2) 2016 Carmassi et al. This work is published and licensed by Dove Medical Press Limited. The full terms of this license are available at https://www.dovepress.com/terms.php
and incorporate the Creative Commons Attribution - Non Commercial (unported, v3.0) License (http://(creativecommons.org/licenses/by-nc/3.0/). By accessing the work you $\mathrm{BY}$
hC for commercial use of this work, please see paragraphs 4.2 and 5 of our Terms (https://www.dovepress.com/terms.php). 
exposure to job stressors. Prevalence rates range from $10 \%$ to $50 \%$, depending on profession, assessment tools, and population. ${ }^{2,3,6-9}$ Literature has increasingly investigated PTSD prevalence rates, both in its full and subthreshold forms, as well as posttraumatic stress symptoms, among these same populations, upon the acknowledgment of the stressful characteristics of this kind of employment. ${ }^{2,7,9}$ Emergency workers, in fact, must cope with a variety of duty-related stressors, including traumatic incident exposure. Accordingly, the Diagnostic and Statistical Manual of Mental Disorders Fifth Edition (DSM-5) itself explicates, among the changes introduced in PTSD diagnostic criteria, that "repeated or extreme indirect exposure to aversive details of the event(s), usually in the course of professional duties (eg, first responders, collecting body parts; professionals repeatedly exposed to details of child abuse) ${ }^{10 "}$ can be considered as a stressor (criterion A4).

Studies aimed at assessing PTSD prevalence rates among emergency unit operators reported values between $10 \%$ and $17 \% .^{9,11-14}$ A study on emergency rescuers serving in London ${ }^{15}$ reported work stress to be the most important morbidity factor, with a PTSD diagnosis reported in 15\% of the individuals exposed to traumatic events while on duty. Clohessy and Ehlers, ${ }^{13}$ in a study on a sample of 56 ambulance service workers of the Oxfordshire Ambulance NHS Trust, found a PTSD prevalence rate of $21 \%$ according to DSM-IV ${ }^{16}$ criteria. The most reported symptoms were intrusive memories (49\%), irritability (51\%), and insomnia (47\%). More recently, Mealer et $\mathrm{al}^{2}$ reported a PTSD diagnosis in $18 \%$ of 332 university hospital nurses in the USA, while PTSD symptoms were reported in $22 \%$ of the same sample. Accordingly, an extensive systematic review ${ }^{17}$ of all empirical articles regarding emergency medical responders and conceptual literature on the constructs of interest in other related populations reported exposure to traumatic events to be between $80 \%$ and $100 \%$, and rates of PTSD higher than $20 \%$. In this same review, a modification of the stress process model is suggested to explain the relationships among occupational stress exposure, PTSD, and high risk of alcohol and other drug use. Most recently, Fjeldheim et al $^{5}$ reported $94 \%$ of 131 South African university paramedic trainees to have directly experienced trauma, with $16 \%$ meeting PTSD criteria and $7 \%$ chronic perceived stress, suggesting the need for efficient, ongoing screening of PTSD symptomatology in trauma-exposed high-risk groups.

Recently, some authors have explored PTSD prevalence rates among emergency workers not only in its full-blown manifestation but also in partial and subthreshold forms. ${ }^{13,18-20}$
Clohessy and Ehlers, ${ }^{13}$ in a study on 56 ambulance service workers in the United Kingdom, found that 21\% of responders met DSM-III-Text Revised criteria for PTSD, while $22 \%$ met screening criteria for psychiatric symptoms. Crabbe et al, ${ }^{21}$ investigating 38 emergency workers, found relevant rates of posttraumatic symptomatology. Mealer et $\mathrm{al}^{2}$ reported PTSD symptoms in $22 \%$ of the nurses operating in a university hospital, while Genest et $\mathrm{al}^{22}$ evidenced the onset of intrusive symptoms in emergency operators who attempted Basic Life Support.

In the framework of an international Italian-American research project, named "Spectrum-Project", between researchers of the Universities of Pisa (Italy), Pittsburgh (USA), Columbia (New York, USA), and California at San Diego (USA), established to develop and test assessment instruments for assessment of the spectrum of clinical features associated with DSM psychiatric disorders, some researchers developed a multidimensional spectrum approach to PTSD. The spectrum model proposed highlights the significance of isolated symptoms and subthreshold symptom clusters that accompany each disorder classified in the DSM, and may follow, or be manifested, in concurrence with the main disorder. ${ }^{23}$ Accordingly, the Trauma and Loss Spectrum Self-Report (TALS-SR) ${ }^{24,25}$ explores the spectrum related to PTSD upon a multidimensional approach across three major dimensions: that of the traumatic event, including the socalled low-magnitude events; that of the acute reaction; and that of the symptomatological clusters including maladaptive behaviors. Most recently, data on the PTSD symptomatological prevalence data according to DSM-5 criteria among survivors to natural and human-made disasters have been reported by some of researchers. ${ }^{26,27}$

Little data are yet available on DSM-5 PTSD prevalence rates among operators of the emergency units in Europe, particularly in Italy. The aim of this study was to assess DSM-5 PTSD, as well as posttraumatic stress spectrum symptomatology, among the staff working in the emergency units of a major university hospital in central Italy. A further aim of this study was to examine the impact of PTSD and posttraumatic stress symptoms on the work and social functioning of the same persons.

\section{Methods \\ Study design}

A total sample of 110 persons employed, at the time of enrollment, at the emergency units (emergency medicine and emergency room) of the "Azienda Ospedaliero-Universitaria Pisana (AOUP)" was included in this study. 
The ethics committee of the University of Pisa approved all the procedures of evaluation and recruitment. Suitable candidates provided written informed consent after receiving an exhaustive description of the study and after having the opportunity to ask any questions in reference to the study.

\section{Instruments and assessment}

All persons were assessed by means of the TALS-SR ${ }^{25}$ for posttraumatic stress spectrum symptoms and the Work and Social Adjustment Scale $\left(W_{S A S}{ }^{28}\right.$ ) for work and social functioning.

The TALS-SR is a questionnaire developed for assessing posttraumatic stress spectrum symptoms. ${ }^{24,25}$ It includes 116 items exploring the lifetime experience of a range of losses and/or traumatic events and lifetime symptoms, behaviors, and personal characteristics that might represent manifestations and/or risk factors for the development of a stress response syndrome. The instrument is organized into nine domains including loss events (I), grief reactions (II), potentially traumatic events (III), reactions to losses or upsetting events (IV), re-experiencing $(\mathrm{V})$, avoidance and numbing (VI), maladaptive coping (VII), arousal (VIII), and personal characteristics/ risk factors (IX). The responses to the items are coded in a dichotomous way (yes/no), and domain scores are obtained by counting the number of positive answers.

In accordance with the aims of the study, all participants were asked to report symptoms related to work-related trauma exposure. According to previous studies ${ }^{29,30}$ a DSM-5 diagnosis of PTSD was assessed by using the following matching between DSM-5 symptoms criteria and TALS-SR items:

- criterion $\mathrm{B}(\mathrm{B} 1=80 ; \mathrm{B} 2=77 ; \mathrm{B} 3=79 ; \mathrm{B} 4=78$; B5 =81);

- criterion $\mathrm{C}(\mathrm{C} 1=86 ; \mathrm{C} 2=87$ and/or 88 and/or 89);

- criterion D (D1 =90; D2 =95; D3 =85; D4 =96; D5 =91; $\mathrm{D} 6=93$; D7 =92); and

- criterion E (E1 =108; E2 =99 and/or 100 and/or 102; and/or 103 and/or 104; E3 =106; E4 =107; E5 =105; $\mathrm{E} 6=109$ ).

Due to the sample characteristics, criterion A was considered satisfied.

The WSAS is a test used to evaluate and measure the work and social adjustment. It includes five items that assess the individual's ability to perform the activities of everyday life and how these are affected in the week prior to the assessment. The first item investigates the work ability of the subject. The second item assesses the ability to cope with household chores such as cleaning the house, looking after the children, and doing the shopping. The third item assesses private recreational activities carried out by the patient, such as going to the cinema, visiting museums, and reading. The fourth and fifth items investigate the family interaction and relationship: in particular, the fourth item investigates the social activities carried out exclusively with people who are not part of the family and includes activities such as parties, tours of pleasure, going clubbing, or going on romantic dates. The fifth item analyzes only the relations with family members with whom the person lives, and whether any problems of the subject under examination have interfered with this type of relationship. Each of the five items is rated on a nine-point scale ranging from 0 (not at all) to 8 (severe interference), so that the total scores are between 0 and 40 .

\section{Statistical analysis}

To compare the groups, we used the chi-square test (or Fisher when necessary) in the case of categorical variables, student's $t$-test for quantitative variables with Gaussian distribution, and Kruskal-Wallis and Mann-Whitney tests for the ones with no Gaussian distribution (see the total score WSAS and the total numbers of PTSD criteria satisfied). To study the relation between the total WSAS scores and the total numbers of PTSD criteria satisfied, we calculated Spearman's correlation coefficient. All the processing statistics were conducted using the Statistical Package for Social Science (SPSS Inc., Chicago, IL, USA), version 22.

\section{Results}

Complete data were available for 83 (75.5\%) persons because the remaining persons gave partial response or no response at all. Of the 83 persons included, 30 (36.1\%) were males and $53(63.9 \%)$ were females, with a mean age $( \pm \mathrm{SD})$ of $40.7 \pm 8.5$ years. In particular, among all the responders, $15(18.1 \%)$ were doctors, 51 (61.4\%) were nurses, and 17 $(20.5 \%)$ were health-care assistants. Further, $59(71.1 \%)$ had a bachelor's degree or an advanced degree (these included not only doctors but also nurses, particularly younger ones who hold a university degree), while the remaining 24 (28.9\%) were not graduates (including both some nurses and all of the health-care assistants). The department in which persons were employed was evaluated for the health-care assistants and the nursing staff only. All the doctors, in fact, were subject to rotation and served alternately in both departments. Among the health-care assistants and nurses, 26 (38.2\%) were serving in the Department of Emergency Medicine, while $42(61.8 \%)$ were working in the emergency room. Clinical and demographic characteristics of the study sample are reported in Table 1. 
Table I Clinical and demographic characteristics of the study sample $(\mathrm{N}=83)$

\begin{tabular}{|c|c|c|c|}
\hline & n (\%) & PTSD, n (\%) & $P$-value \\
\hline \multicolumn{4}{|l|}{ Occupation } \\
\hline Doctors & $15(18.1)$ & I (6.7) & 0.424 \\
\hline Nurses & $5 I(6 I .4)$ & $8(15.7)$ & \\
\hline Paramedics & $17(20.5)$ & $4(23.5)$ & \\
\hline \multicolumn{4}{|l|}{ Sex } \\
\hline Males & $30(36.1)$ & $3(10)$ & 0.451 \\
\hline Females & $53(63.9)$ & $10(18.9)$ & \\
\hline \multicolumn{4}{|l|}{ Age } \\
\hline$\leq 40$ years & $4 \mid(49.4)$ & $5(12.2)$ & 0.578 \\
\hline$>40$ years & $42(50.6)$ & $8(19.0)$ & \\
\hline \multicolumn{4}{|l|}{ Education } \\
\hline Graduated & 59 (7I.I) & $7(11.9)$ & 0.246 \\
\hline Nongraduated & $24(28.9)$ & $6(25.0)$ & \\
\hline \multicolumn{4}{|l|}{ Department ${ }^{\mathrm{a}}$} \\
\hline Emergency medicine & $26(38.2)$ & $3(11.5)$ & 0.476 \\
\hline Emergency room & $42(6 I .8)$ & $9(21.4)$ & \\
\hline Total & $83(100)$ & $13(15.7)$ & \\
\hline
\end{tabular}

Notes: aData about the department relate only to the 68 health-care assistants and nursing staff who were assigned either to the Emergency Room or to the Department of Emergency Medicine.

Abbreviation: PTSD, posttraumatic stress disorder.

With regard to the prevalence of PTSD, 13 persons (15.7\%, confidence interval [CI] 99\%: [5.4\%-26.0\%]) met DSM- 5 criteria for the diagnosis of the disorder: one doctor (6.7\%), four nurses $(23.5 \%)$, and eight health-care assistants (15.7\%). Of these, 3 were males $(10.0 \%)$ and 10 were females (18.9\%); 5 were below the age of 40 years (12.2\%) and 8 over the age of 40 years (19.0). Concerning the education level, seven persons with PTSD had a bachelor's degree (11.9\%), while six had a lower level of education $(25.0 \%)$.

As far as the comparisons of the mean ranks of the total WSAS scores are concerned (mean $\pm \mathrm{SD}$, mean rank), females reported significantly higher scores than males (7.74 \pm 8.16 vs $4.37 \pm 5.79, P=0.022$ ) (Table 2 ).

When correlating the total number of PTSD criterion symptoms satisfied (corresponding to the total number of TALS-SR items corresponding to DSM-5 diagnostic criteria) and the total WSAS scores, we found a moderate/strong significant correlation among health-care assistants $(r=0.565$, $P=0.018)$ and nongraduates $(r=0.428, P=0.037)$. Further, a moderate significant correlation was found among women ( $r=0.310, P=0.024$ ) (Table 3).

Finally, nongraduates had significantly higher TALS-SR Domain IV (reaction to potentially traumatic events) mean scores compared to those of graduates $(6.46 \pm 3.37$ vs $4.81 \pm 3.04, P=0.033)$. Further, a significantly higher proportion of the former category reported at least one maladaptive item on the TALS-SR compared to the latter category (7 [29.2\%] vs 6 [10.2\%], $P=0.045$ ).
Table 2 Comparison of WSAS total mean ( $(\mathrm{SD})$ scores among study groups

\begin{tabular}{|c|c|c|c|}
\hline & \multicolumn{2}{|c|}{ Total WSAS } & \multirow[t]{2}{*}{$P$-value } \\
\hline & $\mathbf{N}$ & Mean \pm SD, mean rank & \\
\hline \multicolumn{4}{|l|}{ Occupation } \\
\hline Doctors & 15 & $4.73 \pm 8.5 \mathrm{I}, 32.73$ & 0.225 \\
\hline Nurses & 51 & $7.02 \pm 7.16,44.87$ & \\
\hline Health-care assistants & 17 & $6.59 \pm 7.96,41.56$ & \\
\hline \multicolumn{4}{|l|}{ Sex } \\
\hline Males & 30 & $4.37 \pm 5.79,34.02$ & 0.022 \\
\hline Females & 53 & $7.74 \pm 8.16,46.52$ & \\
\hline \multicolumn{4}{|l|}{ Age } \\
\hline$\leq 40$ years & 41 & $5.98 \pm 6.55,41.04$ & 0.717 \\
\hline$>40$ years & 42 & $7.05 \pm 8.42,42.94$ & \\
\hline \multicolumn{4}{|l|}{ Education } \\
\hline Graduates & 59 & $5.80 \pm 7.08,39.37$ & 0.117 \\
\hline Nongraduates & 24 & $8.29 \pm 8.44,48.46$ & \\
\hline \multicolumn{4}{|l|}{ Department ${ }^{a}$} \\
\hline Emergency medicine & 26 & $6.27 \pm 6.92,33.33$ & 0.699 \\
\hline Emergency room & 42 & $7.31 \pm 7.59,35.23$ & \\
\hline
\end{tabular}

Notes: ${ }^{2}$ Data about the department relate only to the 68 health-care assistants and nursing staff who were assigned either to the Emergency Room or to the Department of Emergency Medicine.

Abbreviation: WSAS, Work and Social Adjustment Scale.

\section{Discussion}

To the best of our knowledge, this is the first study exploring DSM-5 PTSD prevalence rates, as well as posttraumatic stress spectrum symptoms, in a sample of Italian emergency service workers of a major university hospital. Our results show a PTSD prevalence of $15.7 \%$, with higher, despite

Table 3 Correlations between the total number of PTSD criterion symptoms satisfied and the total WSAS mean scores

\begin{tabular}{|c|c|c|}
\hline & $\mathrm{n}(r)$ & $P$-value \\
\hline \multicolumn{3}{|l|}{ Occupation } \\
\hline Doctors & $15(0.436)$ & 0.104 \\
\hline Nurses & $5 I(0.180)$ & 0.208 \\
\hline Paramedics & $17(0.565)$ & 0.018 \\
\hline \multicolumn{3}{|l|}{ Sex } \\
\hline Males & $30(0.03 \mathrm{I})$ & 0.872 \\
\hline Females & $53(0.310)$ & 0.024 \\
\hline \multicolumn{3}{|l|}{ Age } \\
\hline$\leq 40$ years & $4 I(0.289)$ & 0.067 \\
\hline$>40$ years & $42(0.089)$ & 0.574 \\
\hline \multicolumn{3}{|l|}{ Education } \\
\hline Graduates & $59(0.062)$ & 0.640 \\
\hline Nongraduates & $24(0.428)$ & 0.037 \\
\hline \multicolumn{3}{|l|}{ Department ${ }^{\mathrm{a}}$} \\
\hline Emergency medicine & $26(0.33 I)$ & 0.098 \\
\hline Emergency room & $42(0.28 I)$ & 0.071 \\
\hline Total & $83(0.188)$ & 0.089 \\
\hline
\end{tabular}

Notes: a ${ }^{2}$ ata about the department relate only to the 68 persons of the health-care assistants and nursing staff who were assigned either to the Emergency Room or to the Department of Emergency Medicine.

Abbreviations: PTSD, posttraumatic stress disorder; WSAS, Work and Social Adjustment Scale. 
not significant, percentages among nurses and health-care assistants, women, older persons and nongraduates, as well as in those operating in the emergency room. Nongraduates also reported significantly higher mean scores on the TALS-SR Domain IV, exploring the acute reaction to potentially traumatic events, as well as a significantly higher proportion of persons presenting at least one maladaptive behavior, with respect to operators with graduate degrees. Among women, significantly higher scores on the WSAS also emerged compared to men. When correlating the total number of PTSD criterion symptoms satisfied and the total WSAS scores, a strong significant correlation emerged in health-care assistants and nongraduates, while a moderate significant correlation was found in women.

The PTSD rate reported in the study sample is remarkable if compared to the recently published PTSD prevalence in the Italian general population of $2.3 \%$, diagnosed in accordance with DSM-IV-Text Revised criteria ${ }^{31}$ in the framework of the European Study of the Epidemiology of Mental Disorders (ESEMeD). ${ }^{32,33}$ Although caution has to be adopted because the two studies utilized different methods in the sampling and the diagnostic criteria adopted, and thus data cannot be directly compared, a possible higher vulnerability to the disorder can be seen in this professional category in Italy. If we consider our sample, which enrolled all the staff employed at the AOUP, as being possibly representative of Italian emergency operators, it is important to highlight that we reported a CI 99\% far from the $2.3 \%$ of de Girolamo et al, ${ }^{32}$ and thus the PTSD rates could be considered potentially significantly different $(P<0.01)$. In previous reports, some researchers explored symptomatological PTSD prevalence rates assessed by means of the TALS-SR in accordance with either DSM-IV-TR or DSM-5 criteria in the general population exposed to a massive earthquake, reporting substantial correspondence. ${ }^{29,30}$ This may indirectly corroborate a substantial increase in PTSD rates among emergency workers with respect to the general population in Italy.

Noticeably, our results are also in line with previous reports conducted on rescuers and emergency workers across Europe where PTSD prevalence rates ranging between 10\% and $21 \%$ have been reported. ${ }^{9,11-13,34}$ Clohessy and Ehlers, ${ }^{13}$ exploring a sample of paramedics and emergency medical technicians in the UK, showed that $21 \%$ of enrolled persons were affected by PTSD as diagnosed using both DSM-III and DSM-IV. It is also important to highlight that despite the fact that most of the studies involved nurses and paramedics, only scant data are available on the medical staff. Maia and Ribeiro, ${ }^{35}$ exploring 59 among nurses and medical staff from the National Institute of Medical Emergency in the north of Portugal, reported high exposure to events evaluated as traumatic and low prevalence of PTSD. It is important to note that most of the studies reporting higher PTSD prevalence rates are those conducted on paramedics and nursing staff, with our results showing lower, albeit not significant, rates in doctors compared to the other workers who are in line with these findings. However, caution should be adopted when interpreting our data, as a potential explanation for our findings would be that undergraduate emergency workers typically begin to work with trauma at younger ages than nurses and doctors do. There is evidence, in fact, that younger individuals are at higher risk of developing PTSD from the same trauma as opposed to older peers ${ }^{36}$ and that the more one is exposed to trauma, the higher is his/her risk of developing PTSD; thus, we may argue that having started working at an earlier age makes undergraduate workers more globally exposed to trauma than their colleagues. A third potential bias that should be taken into account in larger samples is related to the reasons for choosing emergency care professions; it is in fact more likely that these may be chosen by individuals with traumatic backgrounds, thus affecting the rates of possible complex PTSD.

There is agreement on the fact that PTSD affects females about twice as much as males, also in Italian samples, with more severe symptomatology..$^{26,33,37-41}$ However, studies exploring the possible confounding role of other risk factors, including work-related training and education, reported conflicting results. ${ }^{42,43}$ Some authors, in fact, highlighted that differences between the sexes may be compensated for by adequate professional training, as shown in rescue workers, police agents, or firefighters, particularly in the United States. ${ }^{43-45}$ Our results seem to be in line with these reports despite needing to be corroborated in larger samples as they might be affected by the fact that a greater percentage of women reported lower education. Similarly, our data are in line with studies reporting a relationship between education level and PTSD. In this regard, epidemiological data from the ESEMeD study in Italy reported significantly higher PTSD rates in persons with lower instruction levels. ${ }^{33}$

As previously mentioned, our results also highlighted significantly higher scores on the TALS-SR Domain IV, exploring symptoms of acute reaction to trauma, and a significantly higher proportion of persons presenting at least one maladaptive behavior, with respect to operators with a graduate degree. Increasing literature has documented the relationship between acute distress reaction and PTSD, highlighting PTSD as the ideal candidate for secondary prevention programs. ${ }^{46,47}$ In this regard, Maia and Ribeiro ${ }^{35}$ 
found peritraumatic dissociation and distress symptoms to be the only predictors of PTSD symptoms among 59 nurses and medical staff from the National Institute of Medical Emergency in the north of Portugal. Maladaptive behaviors, including suicidal behaviors and substance use, fully entered the DSM-5 diagnositc criteria for PTSD and were repeatedly associated with higher severity of the disorder. ${ }^{48-52}$ Fjeldheim et $\mathrm{al}^{5}$ reported a rate of $23 \%$ of alcohol abuse in South African university paramedic trainees who directly experienced trauma. Our data as a whole seem to thus suggest an increased severity of posttraumatic stress reaction in emergency workers with lower educational levels. Consistently, we also found a strong significant correlation between the total number of PTSD symptoms and impairment in work and social adjustment in health-care assistants, nongraduates, and women.

Some important limitations of the study should be borne in mind when interpreting our results. The most important is related to the limited sample size that may impact on the generalizability of our results. However, we underline the novelty of this study, which, to the best of our knowledge, is the first in the literature to report on PTSD and posttraumatic stress spectrum in emergency workers in Italy. Second is the need of a standardized interview such as the Structured Clinical Interview for DSM Disorders to demonstrate the prevalence of PTSD suggested from our symptomatological data. Third, we may argue the fact that most severely avoidant PTSD cases may have not been enrolled because this same symptomatology prevented them from fulfilling the instruments. Fourth, we used a self-report instrument, instead of the rating of the clinician, in order to detect PTSD symptoms and also make the diagnosis and be influenced by co-occurring events. A self-report of PTSD symptoms may in fact be considered less accurate. Nevertheless, the use of TALS-SR allowed us to explore DSM-5 criterion symptoms. Fifth, as already mentioned in our first study, there is the lack of information on the presence of Axis I psychiatric comorbidities.

Despite the limitations mentioned above, this report suggests emergency health professionals to be at high risk for posttraumatic stress spectrum and related impairments in work and social adjustment. The increased vulnerability reported in specific subgroups, particularly women and operators with lower levels of education, should be further investigated in larger samples, with the aim to help identify specific education and training interventions for prevention programs.

\section{Disclosure}

The authors report no conflicts of interest in this work.

\section{References}

1. Jonsson A, Segesten K, Mattsson B. Post-traumatic stress among Swedish ambulance personnel. Emerg Med J. 2003;20:79-84.

2. Mealer M, Burnhamm EL, Goodem CJ, Rothbaum B, Moss M. The prevalence and impact of post traumatic stress disorder and burnout syndrome in nurses. Depress Anxiety. 2009;26(12):1118-1126.

3. Czaja AS, Moss M, Mealer M. Symptoms of posttraumatic stress disorder among pediatric acute care nurses. J Pediatr Nurs. 2012;27(4): 357-365.

4. Iranmanesh S, Tirgari B, Bardsiri HS. Post-traumatic stress disorder among paramedic and hospital emergency personnel in south-east Iran. World J Emerg Med. 2013;4(1):26-31.

5. Fjeldheim CB, Nöthling J, Pretorius K, et al. Trauma exposure, posttraumatic stress disorder and the effect of explanatory variables in paramedic trainees. BMC Emerg Med. 2014;14:11.

6. Pines AM, Aronson E. Career Burnout: Causes and Cures. New York, NY: Free Press; 1988.

7. Embriaco N, Papazian L, Kentish-Barnes N, Pochard F, Azoulay E. Burnout syndrome among critical care healthcare workers. Curr Opin Crit Care. 2007;13(5):482-488.

8. Le Gall JR, Azoulay E, Embriaco N, Poncet MC, Pochard F. Burn out syndrome among critical care workers. Bull Acad Natl Med. 2011; 195(2):389-397.

9. Berger W, Coutinho ES, Figueira I, et al. Rescuers at risk: a systematic review and meta-regression analysis of the worldwide current prevalence and correlates of PTSD in rescue workers. Soc Psychiatry Psychiatr Epidemiol. 2012;47(6):1001-1011.

10. American Psychiatric Association. Diagnostic and Statistical Manual of Mental Disorders: DSM-5. Washington, DC: American Psychiatric Publishing; 2013.

11. Duckworth DH. Psychological problems arising from disaster work. Stress Med. 1986;2:315-323.

12. Hegg-Deloye S, Brassard P, Jauvin N, et al. Current state of knowledge of post-traumatic stress, sleeping problems, obesity and cardiovascular disease in paramedics. Emerg Med J. 2013;31(3):242-247.

13. Clohessy S, Ehlers A. PTSD symptoms, response to intrusive memories and coping in ambulance service workers. Br J Clin Psychol. 1999; 38:251-265.

14. Grevin F. Posttraumatic stress disorder, ego defense mechanisms, and empathy among urban paramedics. Psychol Rep. 1996;79:483-495.

15. Ravenscroft T. Going Critical: GMB/Apex and T\&G Unions 1994 Survey of Occupational Stress Factors in Accident and Emergency Staff in the London Ambulance Service. London, UK: GMB/Apex/and T\&G Unions; 1994.

16. American Psychiatric Association. Diagnostic and Statistical Manual of Mental Disorders, DSM-IV. Washington, DC: American Psychiatric Press; 1994.

17. Donnelly E, Siebert D. Occupational risk factors in the emergency medical services. Prehosp Disaster Med. 2009;24(5):422-429.

18. Jenkins SR, Baird S. Secondary traumatic stress and vicarious trauma: a validational study. J Trauma Stress. 2002;15(5):423-432.

19. Salston M, Figley CR. Secondary traumatic stress effects of working with survivors of criminal victimization. J Trauma Stress. 2003;16(2): 167-174.

20. Berger W, Figueira I, Maurat AM, et al. Partial and full PTSD in Brazilian ambulance workers: prevalence and impact on health and on quality of life. J Trauma Stress. 2007;20(4):637-642.

21. Crabbe JM, Bowley DM, Bofford KD, Alexander DA, Klein S. Are health professionals getting caught in the crossfire? The personal implications of caring for trauma victims. Emerg Med J. 2004;21(5): 568-572.

22. Genest M, Levine J, Ramsden V, Swanson R. The impact of providing help: emergency workers and cardiopulmonary resuscitation attemps. J Trauma Stress. 1990;3:305-315.

23. Cassano GB, Dell'Osso L, Frank E, et al. The bipolar spectrum: a clinical reality in search of diagnostic criteria and an assessment methodology. J Affect Disord. 1999;54(3):319-328. 
24. Dell'Osso L, Shear MK, Carmassi C, et al. Validity and reliability of the Structured Clinical Interview for the Trauma and Loss Spectrum (SCI-TALS). Clin Pract Epidemiol Ment Health. 2008;4:2.

25. Dell'Osso L, Carmassi C, Rucci P, et al. A multidimensional spectrum approach to post-traumatic stress disorder: comparison between the Structured Clinical Interview for Trauma and Loss Spectrum (SCITALS) and the Self-Report instrument (TALS-SR). Compr Psychiatry. 2009;50:485-490.

26. Dell'Osso L, Carmassi C, Massimetti G, Daneluzzo E, Di Tommaso S, Rossi A. Full and partial PTSD among young adult survivors 10 months after the L'Aquila 2009 earthquake: gender differences. J Affect Disord. 2011;131:79-83.

27. Mauri M, Petracca A, Miniati M, et al. Estimates of prevalence and criteria comparison in DSM-5 versus DSM-IV-TR post-traumatic stress disorder in 111 survivors to the 2009 railway accident in Viareggio-Italy. Int J Emerg Ment Health. 2015;17(3):609-615.

28. Mundt JC, Marks IM, Shear MK, Greist JH. The Work and Social Adjustment Scale. A simple measure of impairment in functioning. Br J Psychiatry. 2002;180:161-164.

29. Carmassi C, Akiskal HS, Yong SS, et al. Post-traumatic stress disorder in DSM-5: estimates of prevalence and criteria comparison versus DSM-IV-TR in a non-clinical sample of earthquake survivors. J Affect Disorders. 2013;151(3):843-848.

30. Carmassi C, Akiskal HS, Bessonov D, et al. Gender differences in DSM-5 versus DSM-IV-TR PTSD prevalence and criteria comparison among 512 survivors to the L'Aquila earthquake. J Affect Disorders. 2014;60:55-61.

31. American Psychiatric Association. Diagnostic and Statistical Manual of Mental Disorders, DSM-IV-TR. Washington, DC: American Psychiatric Press; 2000.

32. de Girolamo G, Polidori G, Morosini P, et al. Prevalence of common mental disorders in Italy: results from the European Study of the Epidemiology of Mental Disorders (ESEMeD). Soc Psychiatry Psychiatr Epidemiol. 2006;41(11):853-861.

33. Carmassi C, Dell'Osso L, Manni C, et al. Frequency of trauma exposure and Post-Traumatic Stress Disorder in Italy: analysis from the World Mental Health Survey Initiative. J Psychiatr Res. 2014;59:77-84.

34. Bennett P, Williams Y, Page N, Hood K, Woollard M. Levels of menthal health problems among UK emergency ambulance workers. Emerg Med J. 2004;21:235-236.

35. Maia AC, Ribeiro E. The psychological impact of motor vehicle accidents on emergency service workers. Eur J Emerg Med. 2010;17(5): 296-301.

36. Seal KH, Bertenthal D, Miner CR, Sen S, Marmar C. Bringing the war back home: mental health disorders among 103,788 US veterans returning from Iraq and Afghanistan seen at Department of Veterans Affairs facilities. Arch Intern Med. 2007;167(5):476-482.

37. Kessler RC, Sonnega A, Bromet E, Hughes M, Nelson CB. Posttraumatic stress disorder in the National Comorbidity Survey. Arch Gen Psychiatry. 1995;52:1048-1060.
38. Dell'Osso L, Carmassi C, Consoli G, et al. Lifetime post-traumatic stress symptoms are related to the health-related quality of life and severity of pain/fatigue in patients with fibromyalgia. Clin Exp Rheumatol. 2011;29:S73-S78.

39. Dell'Osso L, Carmassi C, Massimetti G, et al. Age, gender and epicenter proximity effects on post-traumatic stress symptoms in L'Aquila 2009 earthquake survivors. J Affect Disord. 2013;146:174-180.

40. Carmassi C, Antonio Bertelloni C, Massimetti G, et al. Impact of DSM-5 PTSD and gender on impaired eating behaviors in 512 Italian earthquake survivors. Psychiatry Res. 2015;225(1-2):64-69.

41. Dell'Osso L, Carmassi C, Massimetti G, et al. Impact of traumatic loss on post-traumatic spectrum symptoms in high school students after the L'Aquila 2009 earthquake in Italy. J Affect Disord. 2011;134(1-3): 59-64

42. Pole N, Best SR, Weiss DS, et al. Effects of gender and ethnicity on duty-related posttraumatic stress symptoms among urban police officers. J Nerv Ment Dis. 2001;189(7):442-448.

43. Perrin M, Vandeleur CL, Castelao E, et al. Determinants of the development of post-traumatic stress disorder, in the general population. Soc Psychiatry Psychiatr Epidemiol. 2014;49(3):447-457.

44. Dyregrov A, Kristoffersen JI, Gjestad R. Voluntary and professional disaster-workers: similarities and differences in reactions. J Trauma Stress. 1996;9:541-555.

45. Perrin MA, DiGrande L, Wheeler K, Thorpe L, Farfel M, Brackbill R. Differences in PTSD prevalence and associated risk factors among World Trade Center disaster rescue and recovery workers. Am J Psychiatry. 2007;164:1385-1394.

46. Zohar J, Sonnino R, Juven-Wetzler A, Cohen H. Can posttraumatic stress disorder be prevented? CNS Spectr. 2009;14:44-51.

47. Zohar J, Juven-Wetzler A, Sonnino R, Cwikel-Hamzany S, Balaban E, Cohen $\mathrm{H}$. New insights into secondary prevention in post-traumatic stress disorder. Dialogues Clin Neurosci. 2011;13(3):301-309.

48. Dell'Osso L, Carmassi C, Stratta P, et al. Gender differences in the relationship between maladaptive behaviors and post-traumatic stress disorder. A study on 900 L'Aquila 2009 earthquake survivors. Front Psychiatry. 2013;3:111.

49. Dell'Osso L, Carmassi C, Stratta P, Rossi A. Maladaptive behaviours after catastrophic events: the contribute of a "spectrum" approach to post traumatic stress disorders. Heroin Addict Relat Clin Probl. 2012; 14:49-56.

50. Stratta P, Capanna C, Riccardi I, et al. Suicidal intention and negative spiritual coping one year after the earthquake of L'Aquila (Italy). J Affect Disord. 2012;136(3):1227-1231.

51. Dell'Osso L, Stratta P, Conversano C, et al. Lifetime mania is related to post-traumatic stress symptoms in high school students exposed to the 2009 L'Aquila earthquake. Compr Psychiatry. 2014;55(2):357-362.

52. Carmassi C, Stratta P, Massimetti G, et al. New DSM-5 maladaptive symptoms in PTSD: gender differences and correlations with mood spectrum symptoms in a sample of high school students following survival of an earthquake. Ann Gen Psychiatry. 2014;18:13-28.
Neuropsychiatric Disease and Treatment

\section{Publish your work in this journal}

Neuropsychiatric Disease and Treatment is an international, peerreviewed journal of clinical therapeutics and pharmacology focusing on concise rapid reporting of clinical or pre-clinical studies on a range of neuropsychiatric and neurological disorders. This journa is indexed on PubMed Central, the 'PsycINFO' database and CAS,

\section{Dovepress}

and is the official journal of The International Neuropsychiatric Association (INA). The manuscript management system is completely online and includes a very quick and fair peer-review system, which is all easy to use. Visit http://www.dovepress.com/testimonials.php to read real quotes from published authors. 